Acta vet. scand. $1973,14,356-358$.

Brief Communication

\title{
DEMONSTRATION AND ISOLATION OF TRICHINELLA SPIRALIS LARVAE BY A COMBINED DIGESTION AND BAERMANN TECHNIQUE
}

The choice of methods for demonstration of infections with Trichinella spiralis is largely limited to: 1) direct trichinoscopy, 2) extraction of larvae after digestion, 3) serological methods, more especially the indirect immunofluorescence test (IF).

While direct trichinoscopy aims at the microscopical observation of trichina larvae in muscle bits flattened out in a special compressorium, an examination by digestion consists in fermenting the tissue in an aqueous solution of pepsin and $\mathrm{HCl}$, and collecting the larvae thereby released in a Baermann funnel (Gould 1945). For indirect IF a suspension of carefully cleaned trichina larvae is used as antigen (Sadun et al. 1962).

In the following a brief description is given of a method equally usable in the digestion test and in cleaning of extracted larvae for use in, say, serological tests. In principle, the method is based on a previously described modification of the Baermann technique (Henriksen 1965).

$\mathrm{Stage} \mathrm{1.} \mathrm{A} \mathrm{conical} \mathrm{glass} \mathrm{vessel}(750 \mathrm{ml})$ is filled with fermentation fluid $\left(37^{\circ} \mathrm{C}\right)$ to $1 \mathrm{~cm}$ from the rim, and 2 layers of gauze $(15 \mathrm{~cm}$ by $15 \mathrm{~cm}$ ) held together by $2 \mathrm{ab} .20 \mathrm{~cm}$ long wooden rods piercing the corners of the fabric are placed on top of the vessel, with the rods resting on its rim. The central part of the gauze is formed into a pouch submerged in the fluid (Fig. 1).

The muscular tissue to be examined for trichina larvae is finely chopped, and gently deposited at the bottom of the gauze pouch. After $24 \mathrm{hrs}$. at $37^{\circ}-38^{\circ} \mathrm{C}$, larvae released and activated through fermentation of the muscle fibres will have emigrated through the meshes of the gauze and settled at the bottom of the conical vessel. Without decanting the bulk of the fluid the deposit $(0.2-0.3 \mathrm{ml})$ is pipetted off for microscopical examination. 


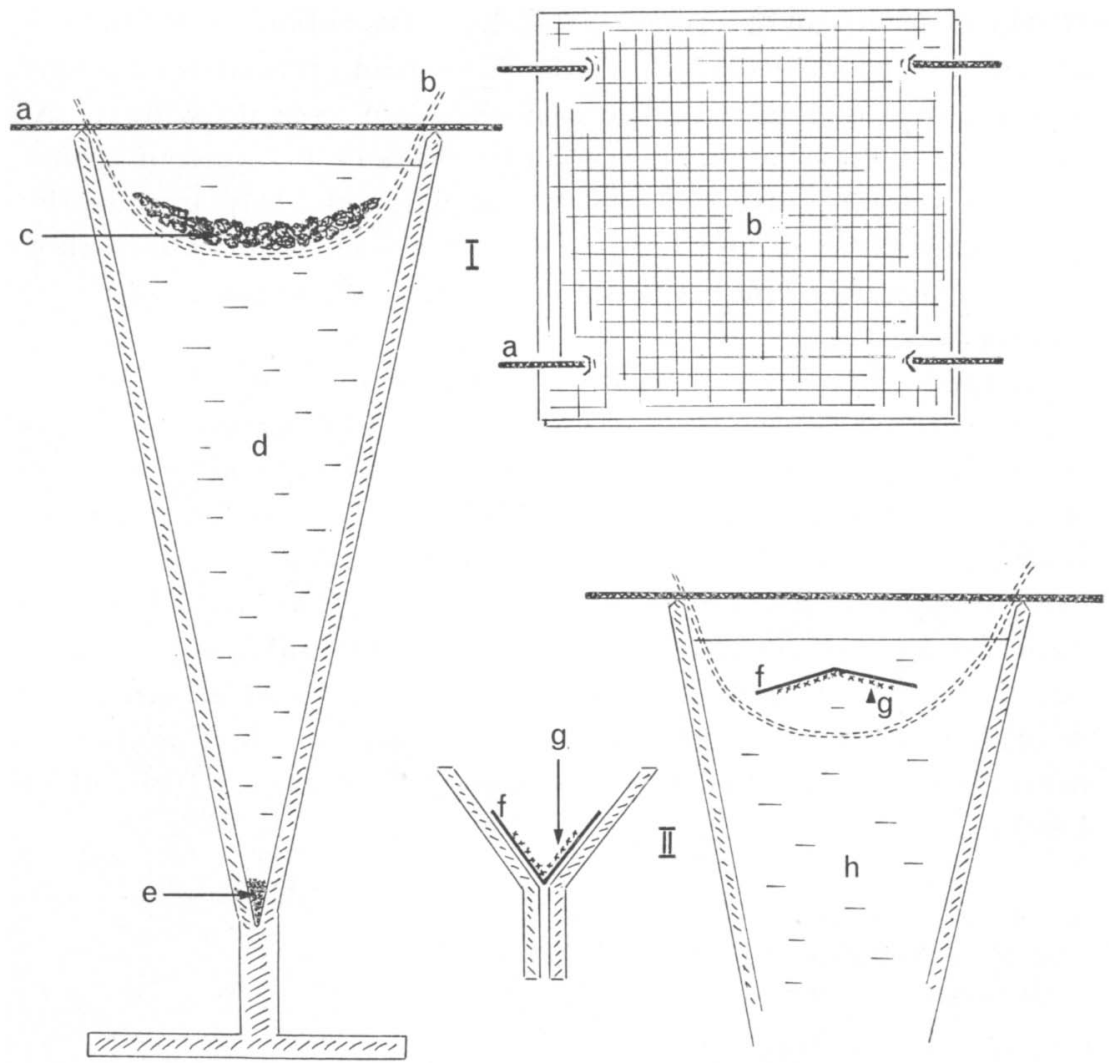

F i g u r e 1. Schematic representation of

I. Digestion combined with extraction of larvae by the Baermann technique.

II. Re-extraction of larvae by the Baermann technique.

a. supporting rods

b. gauze

c. minced tissue

d. fermentation fluid

e. sediment of released larvae

f. filter-paper

g. sediment of larvae on filter-paper

h. buffer solution.

$\mathrm{St}$ a g e 2. For more advanced studies, larvae obtained by digestion of muscular tissue from experimentally infected animals (digestion period limited to 4-6 hrs., if possible) are further purified in the following way: The suspension of larvae is poured onto a folded paper filter (W'hatman 90, diameter $10 \mathrm{~cm}$ ) and the deposit rinsed with $30-50 \mathrm{ml}$ of a suitable buffer 
(PBS). The larvae are re-extracted by a Baermann procedure in PBS at a temperature of $37^{\circ} \mathrm{C}$, the filter being placed very gently in the gauze pouch, with the deposit down (see drawing).* At this stage it may be advantageous to use 4 or 6 layers of gauze. Under these circumstances the larvae will quickly penetrate the gauze and settle at the bottom of the vessel, from where they can be collected. The resulting suspension of larvae is of satisfactory purity.

Compared to other methods, the method described here would seem to offer the following advantages: Besides conical glass vessels and pipettes, which can be autoclaved right after use, the only utensils needed are gauze, wooden rods, and filters, all of which can be destroyed together with the tissue samples. Moreover, the procedure followed in stage 2 makes further rinsing unnecessary, and in addition it secures that only active (live) larvae are collected in that inactive larvae as well as other undesirable particles are trapped in the gauze pouch. Finally, the procedure may be used for eliminating dead larvae from older batches.

\section{Sv. Aage Henriksen}

The State Veterinary Serum Laboratory, Copenhagen, Denmark.

* A technique in principle similar to the one used at this stage in the present work, was described by Taylor (1939) for extraction of nematode larvae from grass samples.

\section{REFERENCES}

Gould, S. E.: Trichinosis. C. C. Thomas, Springfield, Ill., USA 1945.

Henriksen, Sv. Aa.: En forbedret teknik ved unders $\varnothing$ gelse for lungeormlarver i fæces. (An improved technique for the examination of faeces for larvae of lung worms). Nord. Vet.-Med. 1965, 17, $446-454$.

Sadun, E. H., R. J. Anderson \& J. S. Williams: Fluorescent antibody test for the serological diagnosis of trichinosis. Exp. Parasit. $1962,12,423-433$.

Taylor, E. L.: Technique for the estimation of pasture infestation by strongyloid larvae. Parasitology 1939, 31, 473-478.

(Received April 10, 1973).

Reprints may be requested from: Sv. Aa. Henriksen, State Veterinary Serum Laboratory, Bülowsvej 27, DK-1870 Copenhagen V, Denmark. 